\title{
Styles or Cultural Background does Influence the Colors of Virtual Reality Games?
}

\author{
Cecília Sik-Lányi \\ University of Pannonia, Egyetem u. 10, H-8200 Veszprém, Hungary \\ lanyi@almos.uni-pannon.hu
}

\begin{abstract}
Illustrated color of known objects in Virtual Reality (VR) games for various games exhibit characteristic differences. In the first part of our analysis we studied the cartoons' colors, with a great emphasis on whether there are any cultural differences. Coloration of well-known objects depicted in cartoons originating from different parts of the world show characteristic differences. We analyzed several soft-copy and hard-copy cartoons form all over the world and determined what colors the designer use for complexion, sky, water, soil, etc. We continued with the study of VR games' colors. We analyzed eight game categories' colors and determined which colors the designer used for skin, sky, water, grass, etc. These colors were compared with the prototypical memory colors and cartoon colors of these objects. The research quantifies these differences and provides advice to the VR games to be tinted, if they are intended for a specific region of the world and specific VR games. In the second phase of the research such images of films, which were the equivalent of VR games are analyzed. The staining of these films were compared to the corresponding color of VR games and memory color display object.
\end{abstract}

Keywords: Virtual Reality; Game; Film; Color

\section{Introduction}

Many books and articles deal with the question of how colors influence the mood of people seeing them and how, e.g. in a picture the mood of a person can be expressed in colors. For artists, color was always a vehicle to express moods [1]. Panton, as an artist, even gave the title of his booklet: "Choosing colors should not be a gamble. It should be a conscious decision. Colors have meaning and function" [2]. Hutchings [3] discussed the use of colors during the ages, and pointed out that there are cultural differences that should be taken into consideration. Robertson and his colleagues [4] found evidence of cultural and linguistic relativity, among others in color categorization. Analyzing ninety-eight languages Berlin and Kay [5] found that eleven color words act as focal points of all the basic color words in all languages of the world. This set of eleven seems therefore to be a semantic universal. Basic color words are translatable. These 
basic color terms are in English: red, orange, yellow, green, blue, purple, pink, brown, grey, black and white.

Color perception has been a traditional test-case of Whorf's principle of linguistic relativity [6], [7], [8], i.e., the idea that speakers of different languages perceive and process reality and the world differently, influenced by lexical and grammatical distinctions specific to their language. The vast majority of empirical research in the past 17 years has supported the notion [9] that language acts an attention-directing mechanism in the cognitive processing of color, in both offline similarity judgments [7], [4] and online perceptual discrimination [10], [11], [12].

Duncan and Nobs [13] investigated the interrelationship between human emotions induced by colors and their psychophysical stimuli, and found differences between emotional color scales established in Europe and the Far East. Szabo developed predictive mathematical models of color harmony [14] to quantify color harmony impression of observers and a new light source quality metric called Harmony Rendering Index [15] based on these formulae.

Multimedia applications usually use graphical drawings instead of photographs, because they can be more efficiently moved and stored. In many of the cases users regard pictures with less colors appropriate for use. For VR games' simulations it is enough to use homogenly designated pictures, like in the programs for treatment of some kinds of phobias. These pictures will henceforward be called cartoon-like pictures, graphical pictures or simply cartoons.

The graphical designer has to choose from a great amount of hues representing qualities. Most of the multimedia programs enable a wide range of choice of colors from its own palette, and also gives some instructions how and where these colors can be used. Previously the coloring of the pictures was the task of the graphical designer, who learnt his profession. Today, this task is made by the IT engineer programming the animation, or more frequently called animator.

The pictures have an aesthetic value as well, which means that the chosen hues cannot clash and that they have to be in a harmony. There are several guiding principles regarding the harmony of colorization.

In our research we give instructions how to set the colors of different qualities (objects). We created a database, which contains hundreds of pictures' colors from different cultural regions. We categorized hundreds of pictures that are paperbased (henceforth hard-copy) or pictures from the internet (henceforth soft-copy) and also we measured the colors of their different qualities. We evaluated six important and most frequently used qualities (face, grass, sky, lake, foliage, treetrunk) from four different cultural regions. We compared the results with the memory colors.

The above investigations were performed either on single color patches or tried to elaborate on historic findings. We were seeking a different way to be able to compare the preferred coloration of well-known objects by present day population 
- especially young people - coming from different cultural backgrounds. VR games are popular among children and young people all over the world. They are not only popular, but have proved effective when used in special education to teach independent living skills [16], [17], and more latterly by 'modding' popular games engines (such as the Source engine as used in Half-Life 2) to teach employment skills [18], [19].

A lot of 3D games can be found nowadays. There is a huge difference between the properties of game heroes and the properties of real humans. This difference can be seen in the choice of colors to depict the heroes and their surroundings, which is far from what we can see in our everyday life and our environment. The usage of these computer games by children is getting longer and longer every day. The main question can be, whether the colorization of these games have any influence on the children's color sense? If we want to answer this question we have to analyze the input, the colors which are used in games.

Studying cultural differences that impact humans' interaction with information is an emerging field [20], [21, [22]. Inside this field, our research focus on cultural differences of colors. It is known that color may influence human emotions or feelings, in the sense that some colors may make one happy, while some colors may make one depressive [23]. Sato and co-workers split color emotion into three categories (activity, potency and warm-cool) in Japan [24]. Analysis of crosscultural color emotion was investigated in 7 countries [23]. In this study they evaluated 214 color samples on 12 emotion variables by subject from seven different regions in a psychophysical experiment. By factor analysis, it was found that three factors were sufficient to represent 80 "region-emotion" variables. They found that chroma and lightness were the most important factors on color emotion.

Virtual Environment (VE): A synthetic, spatial (usually 3D) world seen from a first-person's point of view. The view in a VE is under the real-time control of the user. Virtual Reality (VR) and Virtual World are more or less synonymous with VE [25]. More specifically, VEs are distinguished from other simulator systems by their capacity to portray three-dimensional (3D) spatial information in a variety of modalities, their ability to exploit users' natural input behaviors for humancomputer interaction, and their potential to "immerse" the user in the virtual world. The effects of human differences in immersive VR environments are a cutting edge research topic $[26,27]$. Inside this area, focusing on cross-cultural aspects is our promising target.

According to Steinkuehler, the current global player populations of the most popular three games that she has studied over the past few years, totals over 9.5 million - a population which rivals, e.g. most US metropolises [28].

These games are used on PC or laptop. In this case there are non immerse VR games. The users observe these games under approximately $30^{\circ}$ visual angle, thus in this respect it is immaterial that people do not see colors outside of approximately $100^{\circ}$ horizontally [29]. Another question is if the player uses these 
games using a Head Mounted Display (HMD). Field of view (FOV) of the HMD gives the world builder yet more compromises to make. Although theory is limited, narrow FOVs may hinder task performances such as maneuvering, grasping objects and locating moving targets [30]. Wider FOVs may improve performance and also feelings of involvement and presence, but this comes at the expense of greater weight and size of the HMD and possibly worse image resolution [31].

Virtual reality games are popular among children and adolescents around the world. The coloring of the heroes and the environments in VR games are very far from the average people and the real environment. Children play VR games every day, so these games affect the aesthetics of the children. The question would be: Do not pay more attention to children experiencing right discoloration of virtual worlds: in this context? In order to provide designers and programmers to pay due attention to these colors in the virtual world, or not?

\section{Colorimetric Fundamentals}

\subsection{Color}

In scientific literature three components of color perception are distinguished: brightness, hue and colorfulness:

- Brightness: the sensation can be almost blending strong, medium or dim and dark.

- Hue is usually shown as a hue circle, where four distinguishable different areas are red, yellow, green and blue.

- Colorfulness has been divided by MacDonald into a five value scale: Starting with gray (achromatic) up to the most brilliant color.

The communication of the color perception can thus be made in the following form: The complexion of the person who stands in front of me is medium bright, moderately vivid and reddish yellow [32], [33].

The color stimulus can be described in a definite way using a color order system. There are several color systems in use RGB, CMYK, CIELAB. We performed our measurements using the CIELAB system, it is the system now recommended by international standards [34]. Figure 1 shows this color system as a three dimensional body, with the lightness, chroma axes and hue circle (or $a^{*}, b^{*}$ axes to describe chroma and hue) where the hue is measured as a hue angle. It provides reasonable uniform color scales in lightness $\left(L^{*}\right)$ and chroma $\left(C_{a b}{ }^{*}\right)$ and gives more or less equidistant scaling along the hue circle $\left(h_{a b} *\right)$. 


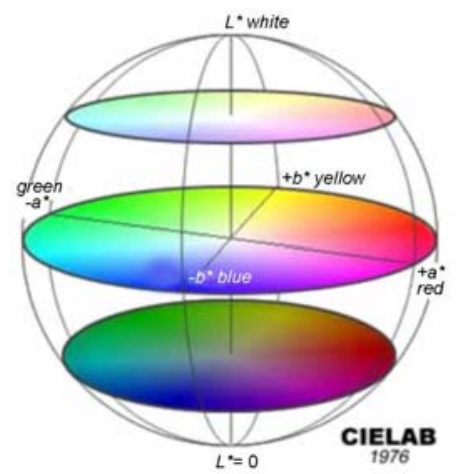

Figure 1

Three-dimensional graph of the real surface colors, in the system of lightness, chroma and hue

\subsection{Memory Colors of Well Known Objects}

The term memory color is used for the color of well-known, often seen objects, as in our brain we attach a color to the given object. Memory colors are well stabilized products of our memory. They are colors we will pick from a high number of color chips if one is asked to show the color chip resembling the color of human complexion, or sky blue, etc. Table 1 shows the $L^{*}, a^{*}, b^{*}$ values of some memory colors [35].

Table 1

Memory colors of well-known objects according to the different authors

\begin{tabular}{|c|c|c|c|}
\hline Memory color & $\mathrm{L}^{*}$ & $h_{\mathrm{ab}}{ }^{*}$ & Reference \\
\hline \multirow{5}{*}{$\begin{array}{l}\text { Caucasian skin } \\
\text { blue sky } \\
\text { green grass } \\
\text { oriental skin } \\
\text { deciduous foliage }\end{array}$} & 79.5 & 32.9 & {$[36]$} \\
\hline & 54.0 & 238.8 & {$[36]$} \\
\hline & 50.0 & 138.5 & {$[37]$} \\
\hline & 63.9 & 49.0 & {$[38]$} \\
\hline & 33.6 & 145.3 & {$[36]$} \\
\hline
\end{tabular}

\section{Measuring Method}

\subsection{Cartoon's Picture Samples Studies}

In our investigations we had to restrict ourselves to pictures where the theme of the picture has some resemblance to the real world, i.e. pictures were not considered, where the coloration was far from what one would accept as a 
"natural" color of an object. For representative pictures and more detailed measurement results see the WEB site of one of the authors

With the start of our research we posed the question that where can we find hundreds of pictures that can appear everywhere in the world? How can we map the pictures that were created by graphical designers during the last decades? The solutions are the cartoons, both in hard-copy and soft-copy. As a first step we collected hundreds of graphical pictures (henceforth we call them cartoons). To reach our aim we tried to categorize them according to cultural regions. The most important categories are the following: European (historical), American (hero, combat), Japanese (so called manga) and Australian (family).

The European carton designers love to depict historical themed stories, here we have also listed the depiction of literary works and situation comedies. These are stories like the French "Asterix and Obelix", or the Hungarian "Mátyás király", "A Pál utcai fiúk", or the English "Tom Sawyer or Huckleberry Finn", etc. Regrettably the real Hungarian cartoon designers have disappeared, however we were able to find a web site (http://rajz.film.hu/), where they wish to restart making the traditional cartoons with a help of a project.

The Americans like completely different types of stories. These are called 'combat' cartoons (Spiderman, Robocop, Superman). In an American cartoon the depiction is completely different from the one we know in Europe. The figures are sketchy; we can feel the movement and dynamics on them. It is interesting that in these cartoons are the facial and body forms depicted in the most natural way. The scenery however is not as important, mostly they depict a figure with a simple one color background. Despite these the Europeans give the background nearly the same prominence like on the characters.

The cartoons which are preferred by the Japanese are the most interesting. The Japanese cartoon designers do not present their characters on the basis of their cultural background. The characters, who are mostly children, are tall, have a long leg, big and colorful eyes and hair, and have a really pale complexion. On the basis of the previous knowledge we can unequivocally divide these cartoons from the previous categories.

We got some sample from the Australians as well, but we could not really categorize them. So we created a new category, based on the Australian type (family). The Australian cartoons' characteristics are nearly the same as we can find in the European or the Japanese types, the figures and the background are clearly distinct, but mostly the scenes are mostly in the present, they are fabular, the colors are natural, there are no unnatural hues, green or purple hairs.

There are cartoon series that have a global distribution, and where prints are made in different countries. One of these is 'Asterix' that has more the 100 translations. Just to get a feel on the differences publishers choose for complexion color we summarized complexion color of "Cleopatra", one of the cartoon characters in the 
series No. 6 "Asterix and Cleopatra" depicted in the Cover Galery of Asterix International in Figure 3. We just inserted the pictures in a graphics program that enabled "eye-drop" technique to fetch the color into the program's color management. As we were interested only in the relative differences between the particular editions, we used the default setting of the program. Table 2

shows the results in increasing CIELAB lightness. As can be seen the Swedish and the American editions use low CIE 1976 lightness, in case of the American edition extremely high CIELAB chroma was found. The next higher lightness was found for the Turkish edition, where the CIELAB hue angle is at the reddish extreme. The Hungarian, Russian, Greek and German editions show complexion colors of higher lightness and low CIELAB chroma. The latter two are also between the most yellowish ones.

As we have downloaded the above samples from the Internet, we have no information on eventual distortions produced by the scanner at the input site, neither on the actual state of the pages scanned. Therefore we do not want to draw major conclusions from this part of the study; it should show only that even for the same fundamental picture if reproduced in different countries color differences would be seen that might be coupled to the regional preference. To get a better insight into the regional differences we investigated cartoons received from different parts of the globe, and compared the coloration used for a number of representative objects.

Table 2

CIELAB co-ordinates of some complexion colors of Cleopatra in the Asterix and Cleopatra series of the Asterix International Cover Galery

\begin{tabular}{|l|c|c|c|}
\hline Edition & $L^{*}$ & $C_{\mathrm{ab}}{ }^{*}$ & $h_{\mathrm{ab}}{ }^{*}$ \\
\hline \multirow{3}{*}{$\begin{array}{l}\text { Useden } \\
\text { Turkey }\end{array}$} & 64 & 76 & 42 \\
\cline { 2 - 4 } Brazil & 67 & 107 & 46 \\
\cline { 2 - 4 } Italy & 67 & 71 & 37 \\
\cline { 2 - 4 } Korea & 70 & 74 & 46 \\
\cline { 2 - 4 } United Kingdom & 70 & 76 & 42 \\
\cline { 2 - 4 } The Netherlands & 71 & 77 & 48 \\
\cline { 2 - 4 } South-Africa & 74 & 62 & 52 \\
\cline { 2 - 4 } Hungary & 74 & 64 & 48 \\
\cline { 2 - 4 } Russia & 76 & 51 & 47 \\
\cline { 2 - 4 } Greece & 78 & 50 & 67 \\
\cline { 2 - 4 } Germany & 82 & 52 & 56 \\
\cline { 2 - 4 } & 83 & 48 & 47 \\
\hline
\end{tabular}




\subsection{The Investigated Representative Hard-Copy Cartoon Colors}

Cartoons have been received from Australia, Europe, Japan and the USA. With the help of a small CCD array based spectroradiometer we determined the spectral reflectance properties of small homogeneous patches (approximately $3 \mathrm{~mm}$ diameter) using incandescent lamp illumination and $45^{\circ} / 0^{\circ}$ measuring geometry. From this CIELAB values were calculated for D65 illuminant and 2 degree standard observer.

Analyzing a high number of cartoons we determined the coloration of the following objects:

- fair, suntanned and dark complexion,

- black, blond, brown and red hair,

- clouds and sky,

- tree trunk, grass, foliage,

- $\quad$ soil, sand and water (lake),

- concrete.

In the following data of six object colors will be detailed: complexion, sky, tree trunk, grass, foliage and water (lake). For better visualization Figure 2 shows average values and standard deviation ellipses for three-three of the analyzed six colors.

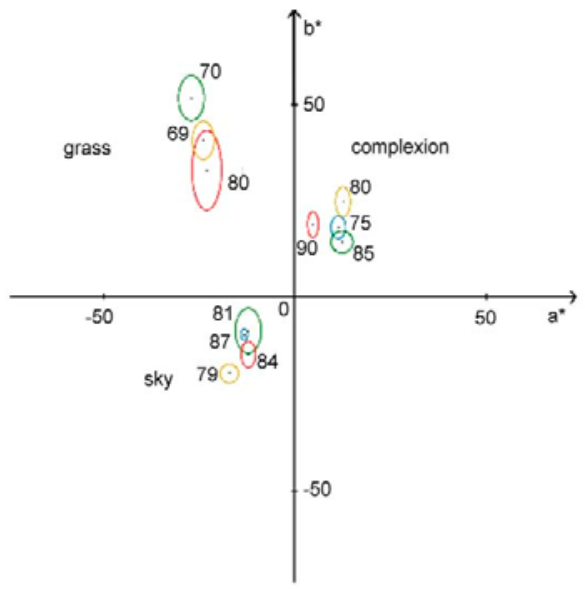

Figure 2

Typical complexion, grass and sky CIELAB values, depicted on an $a^{*}, b^{*}$ diagram, $L^{*}$ values are written in the vicinity of the standard deviation ellipses, shown in blue for American, in green for Australian, in red for Japanese and in yellow for European hard-copy cartoons. 
As an example we can see one of the edition of Asterix's (original) cover (Fig. 3).
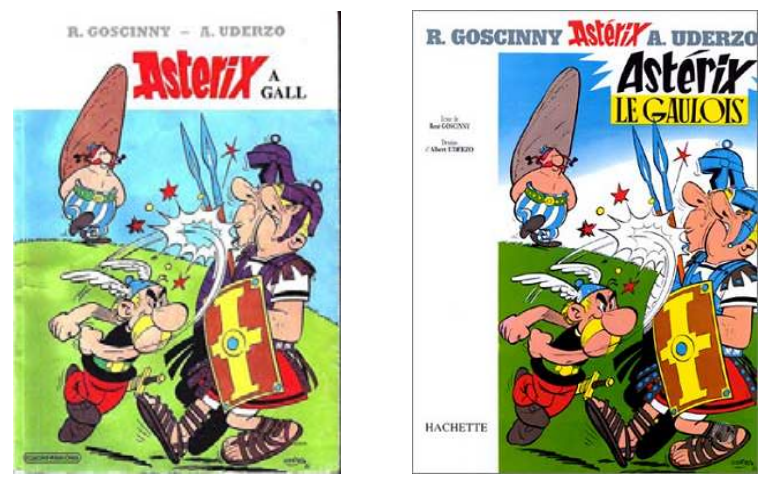

Figure 3

Cover released in Hungary (left side) and cover from France (right side)

\subsection{Representative Soft-Copy Cartoon Colors}

Similar investigations as described in the previous paragraph were performed also on cartoon pictures found on the Internet. The only difference in this case was that the CIELAB co-ordinates were not measured in our laboratory. We supposed that the cartoons were put onto the Internet using sRGB color space, and thus we have set our graphics program to this default state and determined the CIELAB coordinates using the eye-drop facility of the program. Here again we show in Figure 4 average CIELAB values and standard deviation ellipses for three-three of the analyzed six colors.

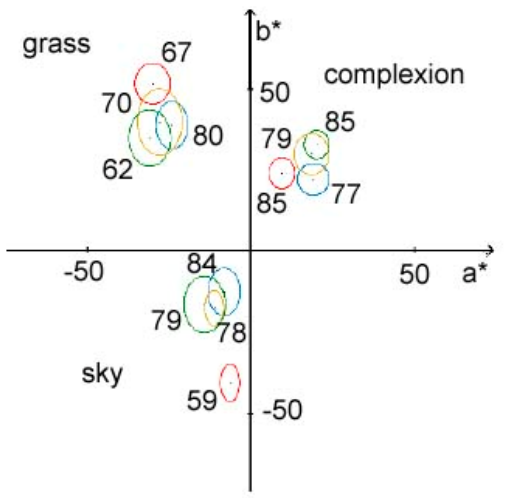

Figure 4

Typical complexion, grass and sky CIELAB values, depicted on an $a^{*}, b^{*}$ diagram, $L^{*}$ values are written in the vicinity of the standard deviation ellipses, shown in blue for American, in green for Australian, in red for Japanese and in yellow for European soft-copy cartoons. 
Table 3

Numerical data of hues of objects on the Hungarian and French covers

\begin{tabular}{|c|c|c|c|c|}
\hline Object & & $L^{*}$ & $a^{*}$ & $b^{*}$ \\
\hline \multirow{2}{*}{ Grass } & HU & 80 & -36 & 59 \\
& FR & 50 & -36 & 52 \\
\hline \multirow{2}{*}{ Sky } & HU & 88 & -27 & -18 \\
& FR & 69 & -10 & -46 \\
\hline \multirow{2}{*}{ Face } & HU & 87 & 12 & 23 \\
& FR & 73 & 34 & 35 \\
\hline \multirow{2}{*}{ Rock } & HU & 57 & 34 & 22 \\
& FR & 57 & 15 & 4 \\
\hline \multirow{2}{*}{ Moustache } & HU & 96 & -14 & 79 \\
& FR & 88 & -3 & 82 \\
\hline
\end{tabular}

In Table 3 we can see the differences between the two pictures' hue usage. One of the most noticeable differences is that the Hungarian release uses lighter colors. During the analysis of the grass color there is not a great differences between the $a^{*}$ and $b^{*}$ value. However the other values show some characteristic differences, the "Hungarian" sky is greenish, the rock is brownish. The French face is reddish and darker.

According to the data shown above, we can assess, that we can get realistic results from the measurement of the hues of objects, if the models were made in equal conditions. This was the reason why we collected cartoons from other parts of the world. We succeeded to collect some cartoons from Australia, Japan, Korea, America and France. Unfortunately there are no cartoons on the market that has been drawn and printed in Hungary. We did not dare to analyze twenty year old cartoons, because the quality of paper and the printing technologies have changed a lot through the last decades, and our results could not be compared with the results from the cartoons, that we got from the other countries. To conclude, we only measured the parts of pictures from original cartoons. This way we would also like to thank the people, who were so kind as to send us some cartoons from abroad.

\subsection{Measuring the Colors of VR Games}

Most popular virtual games were categorized into eight groups, as can be seen in Table 2. Pictures have been downloaded from the Internet of 89 VR games: 7-10 pictures from every game, altogether 752 pictures. Movie films, corresponding to the above films have also been analyzed, 179 pictures from 20 films have been downloaded from the internet. The category of games we used in our research is shown in Table 4. 
Table 4

Categorization of the most popular virtual games

\begin{tabular}{|c|c|c|}
\hline Name of the game category & $\begin{array}{c}\text { Number of the game } \\
\text { category }\end{array}$ & $\begin{array}{c}\text { Number of the film } \\
\text { category }\end{array}$ \\
\hline Action, Adventure, Mystery Games & G1 & F1 \\
\cline { 2 - 3 } Children's Games & G2 & F2 \\
\cline { 2 - 3 } $\begin{array}{c}\text { Driving \& Racing } \\
\text { First-person Shooters } \\
\text { Simulations } \\
\text { Role-playing Games } \\
\text { Strategy } \\
\text { Sports }\end{array}$ & G3 & - \\
\cline { 2 - 3 } & G4 & F4 \\
\cline { 2 - 3 } & G5 & F6 \\
\cline { 2 - 3 } & G6 & - \\
\cline { 2 - 3 } & G7 & - \\
\hline
\end{tabular}

\subsection{Games Categories}

Title of games, from which pictures were taken can be seen as enumerated below.

\section{Action, Adventure, Mystery Games:}

Tomb Raider 7

Edition

Silent Hill 4: The Room

Alone in The Dark: The New Nightmare

GTA San Andreas

Resident Evil 4

Legend of Zelda: The Twighlight Princess

Myst V: End of Ages

Syberia II

The House of the Dead III

Classic

Monkey Island 4

\section{Driving \& Racing:}

Need For Speed Underground II

Nascar 2005: Chase for the Cup

Colin McRae Rally 2005

TOCA Race Driver 2

Assault

Gran Turismo 4

Driv3r

Hot Wheels Stunt Track Challenge

\section{Children's Games:}

Fame Academy: Dance

Camgoo + Webcam

Shrek 2 Team Action

Jimmy Neutron Boy Genius

Robots

Spongebob Squarepants:

Battle for Bikini Bottom

Harry Potter

Quidditch World Cup -

\section{First-person Shooters:}

Counter-Strike Source

Day of Defeat Source

Battlefield 1942

Medal of Honor Pacific

James Bond 007: Nightfire

Call of Duty

Doom 3

Unreal Tournament

Maxpayne II

Star Warp Rep. Commando 
Simulations:

Sim City 4

The Sims 2

Microsoft Flight Simulator 2004

Animal Crossing (Game Cube-ra)

Will of Steel

Empire

F/A-18: Operation Desert Storm

Pacific Fighters

IL-2 Sturmovik - Forgotten Battles

\section{Strategy:}

Cossacks II: Napoleonic Wars

Warcraft III (The Reign of Chaos

- The Frozen Throne)

Heroes of Might and Magic III - IV

Rome: Total War

Blitzkrieg II

Age of Mythology

Warlords 4

2005

Warhammer 40k

Imperial Glory

\subsection{Film Categories}

Action, Adventure, Mystery:

Lara Croft: Tomb Raider

Lara Croft and the Cradle of Life:

......Tomb Raider 2

Silent Hill

Alone in The Dark

Secrets

Resident Evil

Resident Evil: Apocalypse

Azkaban

\section{First-person Shooters:}

James Bond:The World is Not Enough James Bond: Die Another Day

Doom

Star Wars: Episode I - The Phantom Menace

Star Wars: Episode II - Attack of the Clones

Star Wars: Episode III - Revenge of the Sith

\section{Role-playing Games:}

Final Fantasy X - XII

World of Warcraft

Lineage II

Ragnarok Online

Ultima Online Samurai

Guildwars

Chrono Cross

\section{Sports:}

Ski Racing 2005

MVP Baseball 2005

NHL 2005

FIFA 2005

NBA Live 2005

Fight Night Round 2

Madden NFL 2005

Tiger Woods PGA Tour

\section{Children's:}

Shrek

Shrek2

Robots

Harry Potter and the Sorcerer's Stone

Harry Potter and the Chamber of

Harry Potter and the Goblet of Fire

Harry Potter and the Prisoner of

\section{Role-playing:}

Final Fantasy: The Spirits Within 


\subsection{Samples Studies}

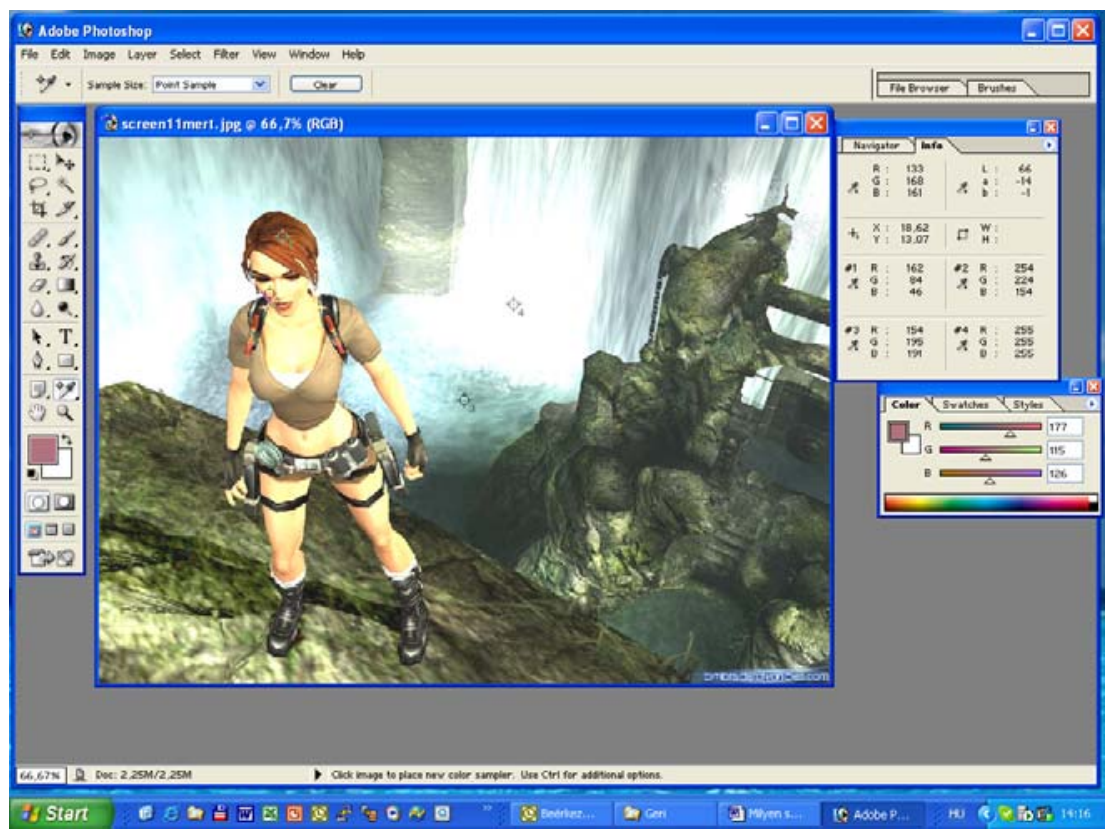

Figure 5

Color measurement in Photoshop, using the eye-drop tool, example is the Tomb Raider play.

1. measurement point: red hair, 2. measurement point: bright face,

3. measurement point: water, 4.measurement point: whitest point in the picture.

We selected objects to be measured for example skin (caucasian face skin, african skin), hair, sky, grass, trunk, cloud, water (lake, river, sea), brick, concrete (road) and so on.

During the investigations we wanted to stay within the bound of theme of pictures, where we have some resemblance to the real world, i.e. pictures where the coloration would not be accepted as a "natural" color of an object, were not considered, i.e. where a specific state of the mind of the hero (e.g. greed, anger, etc.) were emphasized by the designer of the game.

The pictures from the virtual games, which we analyzed, were downloaded from the Internet, supposing that these pictures were put on the Internet using sRGB color space. Our measurements were taken in the CIELAB color space. Sample Tool of Adobe Photoshop was used for sampling (Figure 5). Of $L^{*}, a^{*}, b^{*}$ values nearly 4500 determinations were made. $h_{\mathrm{ab}}$ hue angle and its standard deviation $\left(\Delta h_{\mathrm{ab}}\right)$ was calculated $\left(h_{\mathrm{ab}}=\arctan \left(b^{*} / a^{*}\right)\right)$, together with the chroma $\left(C_{\mathrm{ab}}\right)$ and its standard deviation, from the $L^{*}, a^{*}, b^{*}$, which enabled to determinate the changes in dimensions near to those of perceptions. 


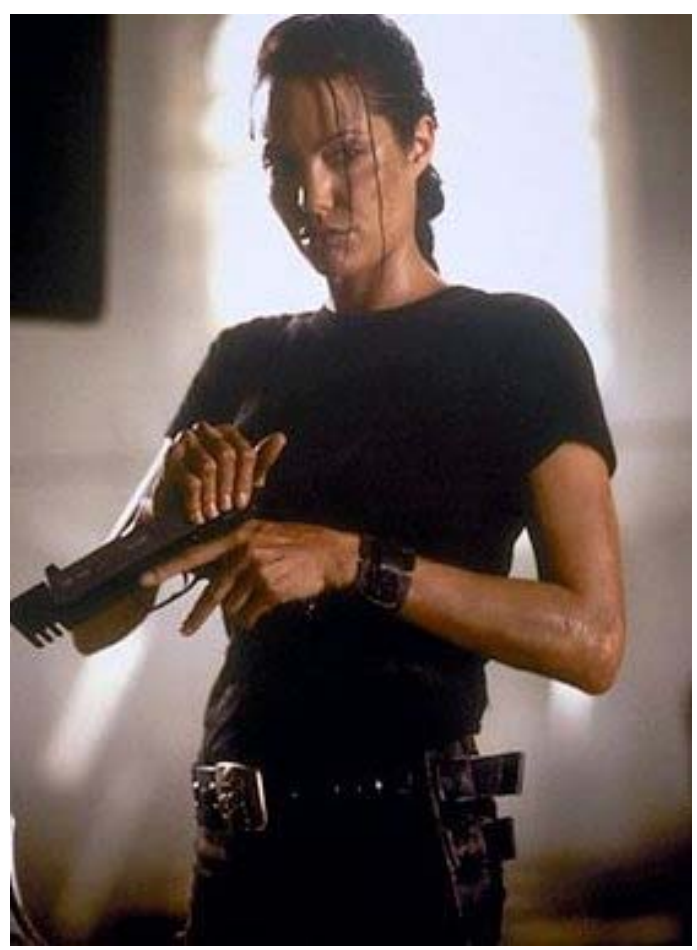

Figure 6

Picture's colors measured of Lara Croft Tomb Raider film

Tables 6 and 7 show the average CIELAB $L^{*}, a^{*}, b^{*}, h_{\mathrm{ab}}$ and $\Delta h_{\mathrm{ab}}$ values by game and film category. (Where the value is missing, there was no appreciable sample.)

Table 6

The average CIELAB $L^{*}, a^{*}, b^{*}, h_{a b}$ and $\Delta h_{a b}$ values by game category

\begin{tabular}{|c|c|c|c|c|c|c|}
\hline $\begin{array}{c}\text { Measured } \\
\text { objects }\end{array}$ & $\begin{array}{c}\text { Game } \\
\text { Category }\end{array}$ & $L^{*}$ & $a^{*}$ & $b^{*}$ & $h_{a b}$ & $\Delta h_{a b}$ \\
\hline \multirow{4}{*}{$\begin{array}{c}\text { Caucasian } \\
\text { face skin }\end{array}$} & $\mathrm{G} 1$ & 65.12 & 13.32 & 21.83 & 60.82 & 15.80 \\
\cline { 2 - 7 } & $\mathrm{G} 2$ & 76.67 & 14.00 & 25.38 & 73.38 & 64.90 \\
\cline { 2 - 7 } & $\mathrm{G} 3$ & 55.00 & 26.00 & 25.00 & 43.88 & \\
\cline { 2 - 7 } & $\mathrm{G} 4$ & 51.44 & 13.56 & 20.29 & 57.23 & 21.86 \\
\cline { 2 - 7 } & $\mathrm{G} 5$ & 71.00 & 22.00 & 31.00 & 54.80 & 4.72 \\
\cline { 2 - 7 } & $\mathrm{G} 6$ & 69.93 & 18.93 & 26.67 & 56.49 & 9.07 \\
\cline { 2 - 7 } & $\mathrm{G} 7$ & 83.00 & 12.00 & 35.00 & 71.08 & \\
\cline { 2 - 7 } & $\mathrm{G} 8$ & 57.18 & 18.59 & 19.91 & 46.43 & 10.09 \\
\hline & $\mathrm{G} 1$ & 59.53 & -1.71 & -12.43 & 221.30 & 74.10 \\
\cline { 2 - 7 } & $\mathrm{G} 2$ & 60.17 & -7.91 & -33.39 & 253.03 & 27.88 \\
\cline { 2 - 7 } & $\mathrm{G} 3$ & 54.60 & -3.08 & -22.66 & 257.56 & 23.92 \\
\hline
\end{tabular}




\begin{tabular}{|c|c|c|c|c|c|c|}
\cline { 2 - 7 } sky & G4 & 65.17 & -2.37 & -11.03 & 226.39 & 75.98 \\
\cline { 2 - 7 } & G5 & 67.42 & 0,36 & -29.39 & 270.51 & 8.05 \\
\cline { 2 - 7 } & G6 & 61.12 & -0.68 & -31.04 & 266.48 & 17.88 \\
\cline { 2 - 7 } & G7 & 70.95 & -5.32 & -22.14 & 256.80 & 17.76 \\
\cline { 2 - 7 } & G8 & 56.00 & -1.10 & -28.30 & 265.52 & 18.25 \\
\hline \multirow{6}{*}{ grass } & G1 & 44.47 & -9.60 & 28.57 & 108.40 & 15.97 \\
\cline { 2 - 7 } & G2 & 38.26 & -25.42 & 32.26 & 128.17 & 8.91 \\
\cline { 2 - 7 } & G3 & 42.92 & -6.04 & 23.04 & 105.62 & 9.79 \\
\cline { 2 - 7 } & G4 & 38.79 & -4.07 & 21.93 & 101.27 & 8.40 \\
\cline { 2 - 7 } & G5 & 43.57 & $-15,50$ & 26.86 & 116.29 & 15.69 \\
\cline { 2 - 7 } & G6 & 36.25 & -12.85 & 28.80 & 114.55 & 11.82 \\
\cline { 2 - 7 } & G7 & 41.73 & -13.84 & 32.90 & 112.45 & 12.19 \\
\cline { 2 - 7 } & G8 & 44.85 & -17.37 & 32.46 & 118.74 & 8.89 \\
\hline
\end{tabular}

Table 7

The average $L^{*}, a^{*}, b^{*}$ coordinates as well as the calculated $h_{a b}$ and its scatter $\Delta h_{a b}$ values for the most important six parts of the picture for each film which has a corresponding game

\begin{tabular}{|c|c|c|c|c|c|c|}
\hline $\begin{array}{c}\text { Measured } \\
\text { objects }\end{array}$ & $\begin{array}{c}\text { Game } \\
\text { Category }\end{array}$ & $L^{*}$ & $a^{*}$ & $b^{*}$ & $h_{a b}$ & $\Delta h_{a b}$ \\
\hline \multirow{3}{*}{$\begin{array}{c}\text { Caucasian } \\
\text { face skin }\end{array}$} & $\mathrm{F} 1$ & 67.09 & 17.09 & 19.27 & 64.85 & 70.77 \\
\cline { 2 - 7 } & $\mathrm{F} 2$ & 69.08 & 15.00 & 15.62 & 65.97 & 71.85 \\
\cline { 2 - 7 } & $\mathrm{F} 4$ & 58.05 & 17.00 & 23.30 & 52.91 & 12.17 \\
\cline { 2 - 7 } sky & $\mathrm{F} 6$ & 50.57 & 13.71 & 12.71 & 78.96 & 92.58 \\
\hline \multirow{4}{*}{ grass } & $\mathrm{F} 1$ & 95.00 & 3.00 & -5.50 & 281.12 & 53.30 \\
\cline { 2 - 7 } & $\mathrm{F} 2$ & 70.23 & -5.08 & -28.38 & 241.57 & 54.74 \\
\cline { 2 - 7 } & $\mathrm{F} 4$ & 70.78 & -2.78 & -13.89 & 224.82 & 59.94 \\
\cline { 2 - 7 } & $\mathrm{F} 6$ & 71.67 & 6.33 & -11.67 & 295.82 & 22.71 \\
\cline { 2 - 7 } & $\mathrm{F} 1$ & 37.67 & -2.33 & 15.33 & 99.01 & 5.08 \\
\hline & $\mathrm{F} 2$ & 52.47 & -13.47 & 39.20 & 110.22 & 15.84 \\
\hline & $\mathrm{F} 4$ & 74.00 & -19.00 & 49.00 & 111.19 & \\
\hline \multirow{3}{*}{} & $\mathrm{F} 6$ & & & & & \\
\hline
\end{tabular}

\section{Discussion}

It seems that comparing the choice of colors used in virtual games [39] with the colors used in cartoons and the so called prototypical colors, which people mentally link with the colors of some objects, are of great interest. We compared results of studies by Sik Lanyi and coworkers [40], who investigated the usage of color shades in cartoons all over the world, with the colors of objects in our research, and with the ones determined by Tarczali [37] and Bartleson [36] for 
memory colors. Sik Lanyi [40] found that there are characteristic differences between both of hard- and soft-copies (i.e. printed cartoons and downloaded images from the Internet) of cartoons originating from different parts of the world.

Complexion color: The lightest of all complexions is the Japanese, followed by the Australian. The darkest complexion color is the American both in soft- and hardcopy. Interesting facts is that the Japanese uses the palest and the least reddish color scale of all. We can observe that the memory color is much more pinkish than the cartoons use for depicting complexion colors. For depicting a sun tanned complexion we could find nearly the same tendency, where the Japanese is the lightest and its chromaticity is closely related to the European one, and the Australian is the pinkest. The memory color is the darkest. Average games use a more yellowish color than the cartoons and the memory colors. The most beautiful face colors were found to be the G2, G5 and G7 face colors. The others use colors that are far from the memory colors. The colors which correspond to the natural complexion colors are used in G2, G5 and G7 games, while the other games use a scale, which are very far from memory colors.

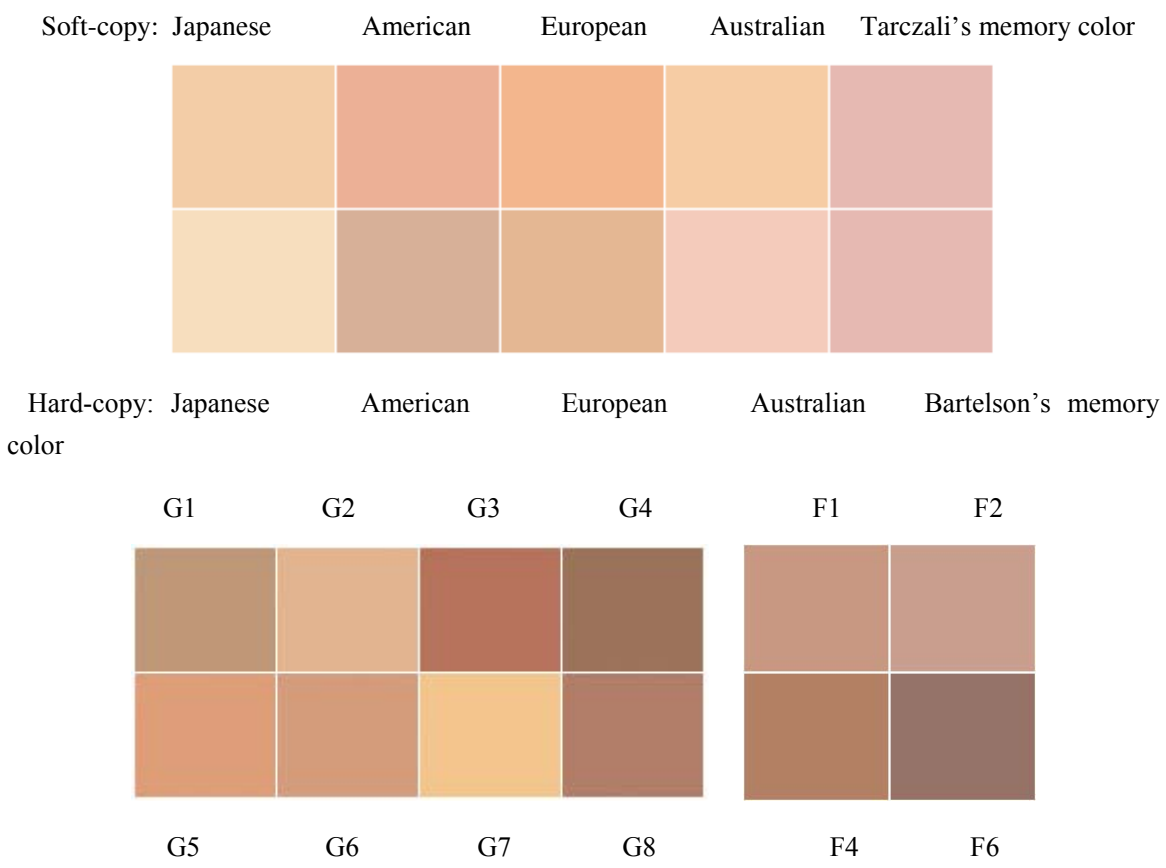

Our measured average Caucasian complexion colors.

Figure 7

Comparison of the Caucasian complexion colors 
In the films much larger scatter was found among the different samples, but the average values did not deviate much from the game samples, in most cases they were slightly lighter, an exception was the F6, where the average value of the Caucasian complexion color turned out to be much darker than in the games. As we had only one such film in our database, with some very special scenes, from this no direct conclusion can be drawn (Figure 7 and Figure 10-11).

Grass color: As for the grass color we can see several differences as well. The soft-copy grass color of the Japanese is much darker than the one of the hard-copy. The American or the European do not use such a yellow shade as the Japanese and the Australian. The memory colors, as well as the cartoon colors are all lighter determined in the mentioned two groups. The average colors of the grass in the virtual games are shown in the lower row. The only acceptable grass colors are G2 and G8. The others are more brownish than the memory colors. As for the film colors, most of the grass and foliage samples were of background values, which produced in the F1 category very dark colors, but e.g. in F2 and F4 films the colors of the grass correspond to the real life grass shade (notwithstanding the colors in games, the lightness was higher, resembling the real grass hue, which is, despite the memory color, more yellowish- Figure 8 and Figure 10-11).

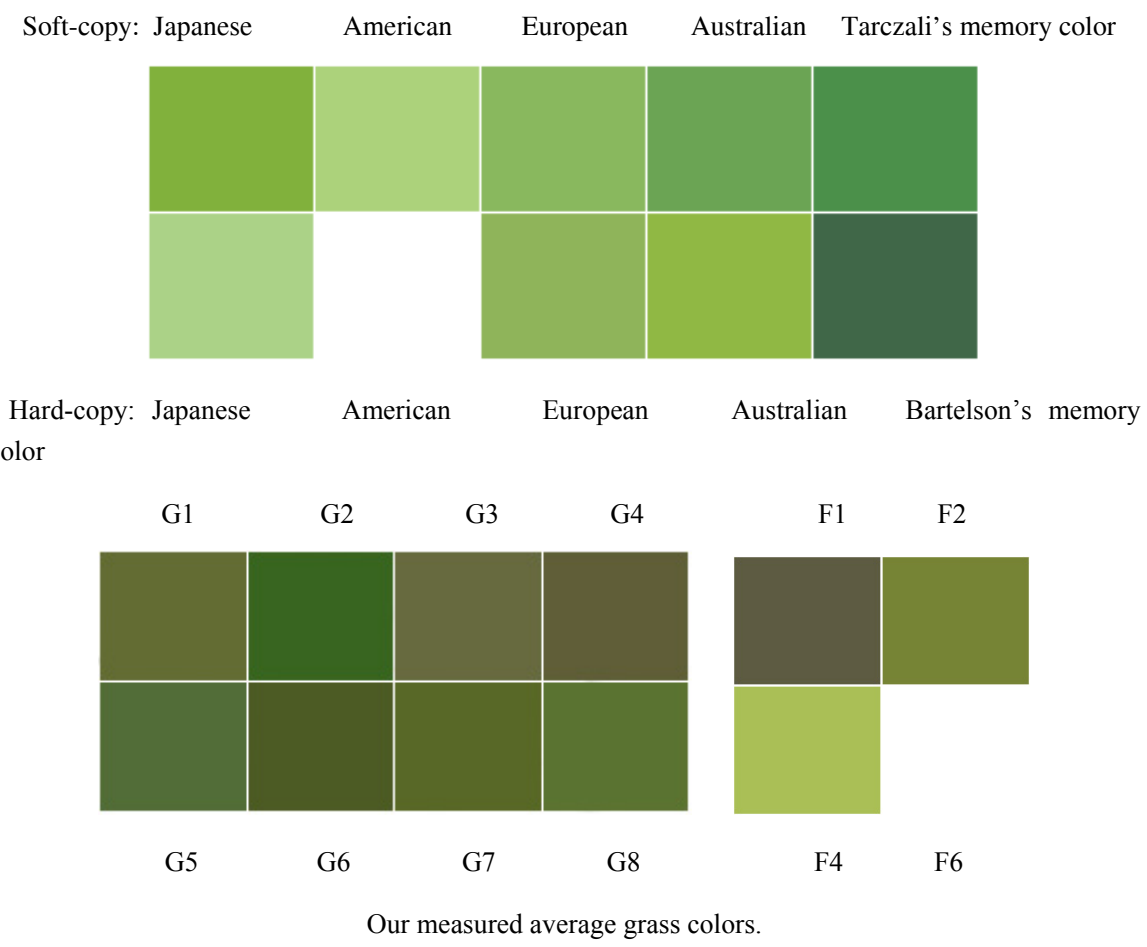

Figure 8

Comparison of the grass colors 
Sky color: In the case of sky colors the cartoon designers use a much more lighter hue, than the memory color. The only exception is the Japanese soft-copy, which uses a quite dark shade. The sky colors used at the G1 and G4 are very grey. Films usually use a brighter color than the equivalent games, which is in the case of F1 almost white. In F6, the hue angle turned out to be extremely violet (Figure 9 and Figure 110-11).

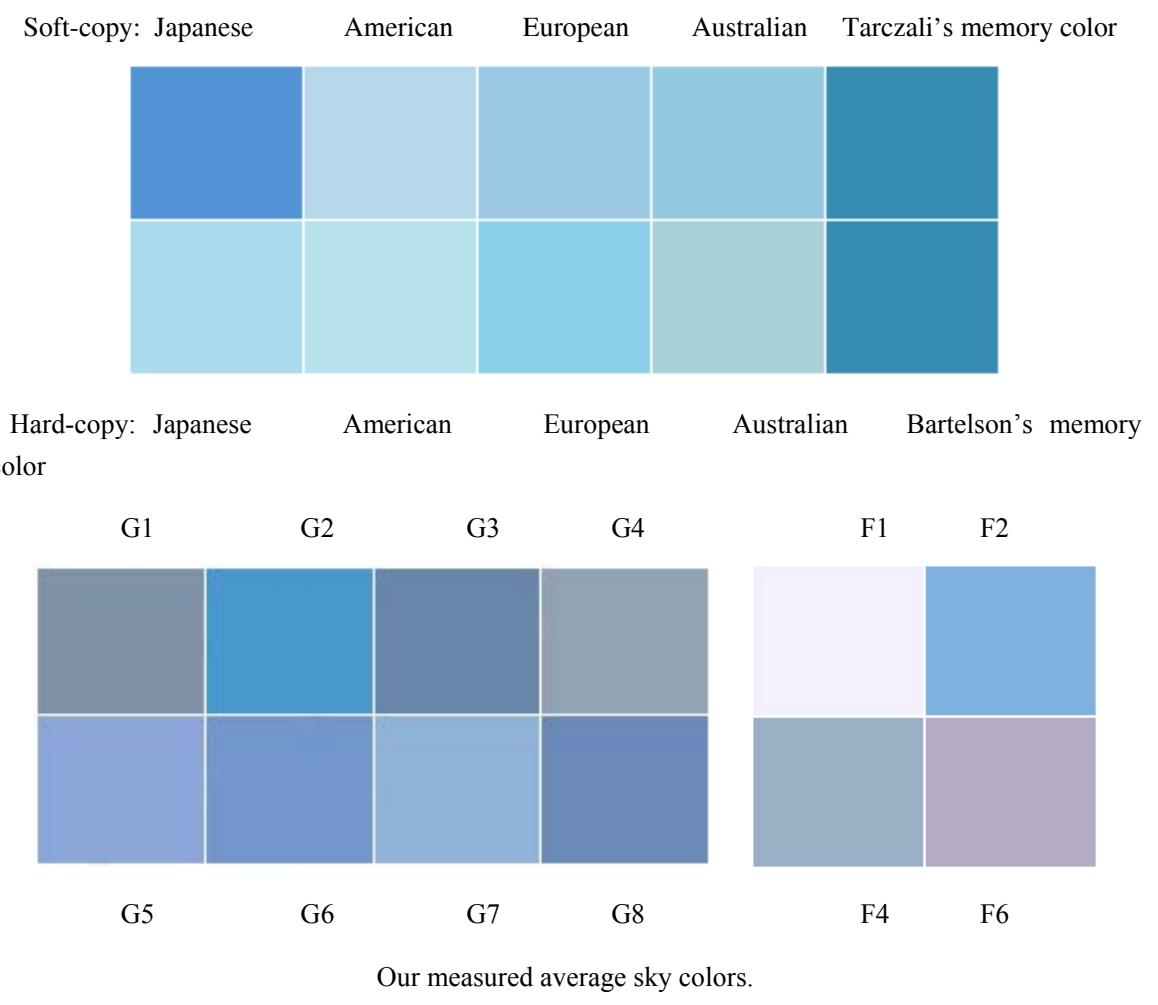

Figure 9

Comparison of the sky colors

\section{Summary and Conclusion}

Characteristic differences were found between the uses of colors for well-known objects in the different global regions. Designers can use these results if they have to prepare e.g. multimedia presentations for different observers.

In Japanese cartoons prepared for Internet presentation, stronger, more saturated colors are used, sometimes with lower lightness. In Europe the paler colors are preferred. This is true for most objects, except for complexion, where the Japanese use the palest colors and but it is interesting that the hue angle is larger than the one found in European complexion colors. 
The situation is different in the case of printed cartoons. In print the Japanese use paler colors, and the most vivid colors are found in Australian pictures. American cartoon artists do not often try to use colors that resemble those of real life objects.

The prototypical memory colors are in most cases much darker then the colors used in the cartoons.

Different virtual reality games show some characteristic differences in the use of colors for some well-known objects. Our results can be presented with the help of some pictures. We took a picture from a book for outline drawings for painting, where the objects, whose colors were investigated (wood, grass, sky, etc.) were available, and painted it with Photoshop, to help the visualization of the colorimetric data. We colored these pictures according to the different game categories (Figure 10) and film categories (Figure 11) as well.

Looking at the pictures one has to consider the following: we used the most usual sky color for painting the sky, cloud color for clouds, tree trunk color for tree trunks, foliage color for leaves of bushes and trees, grass color for grass, and also the little pond on the lower right corner was painted with the average water color for every given game type. The girl on the left side of the picture was painted with the Caucasian complexion color, and the girl on the right side with the complexion color found for Afro-American persons was used. (Objects left white in the pictures do not serve enough examples to investigate.) In the cases of G1 and G4 game categories it is very interesting, that the color of the water in the right lower corner brings to mind the color of concrete road not of water, the sky is rather grey than blue, and the colors of grass and foliage are basically of same hue. Observe also the differences in foliage and grass as well as soil, sand, sky and water colors.
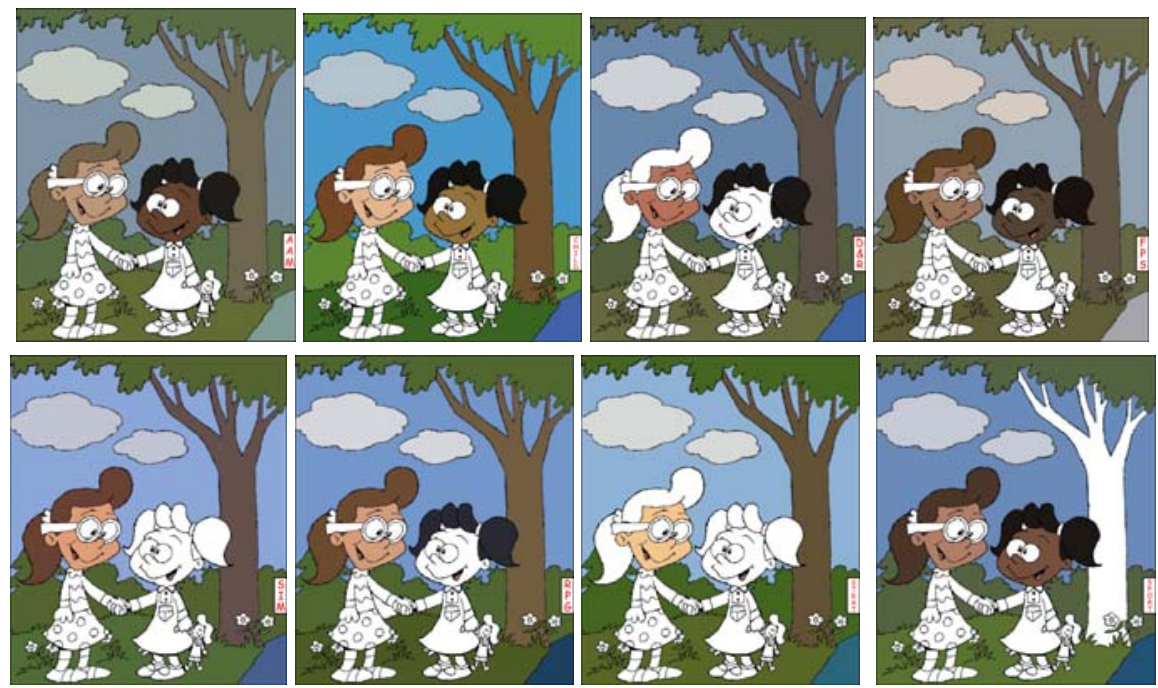

Figure 10

The same picture colored according the style used in different game categories: upper range: G1,G2,G3,G4, lower range: G5,G6,G7,G8 
Inadequately, the designers of virtual games do not take care of using natural colors, which are far from the memory colors too.

During the investigations we found out, that designers use colors to emphasize the message of scenes, and the heroes' state of mind, and they forget about finding and using colors which harmonize with the colors of real world.
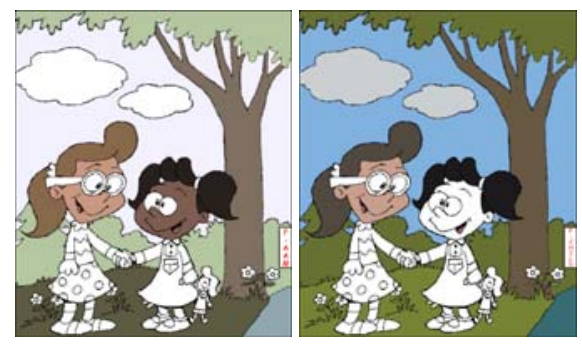
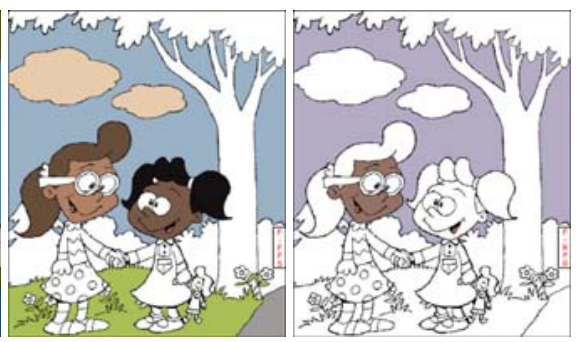

Figure 11

The same picture colored according the style used in different film categories: F1,F2,F4,F6

To make it perfectly clear, we would like to add, that in these virtual games we see fake colors [39], [40]. We would also like advise the designers of virtual games to use more natural shades of colors, which are more related to real ones.

\section{Acknowledgements}

The author thanks the help of her sons Andras Sik and Gergely Sik to download the pictures of the games and helping in the measurements. We want to thank for Veronika Végh, who has collected the cartoons and has helped us with the measurements.

\section{References}

[1] Itten V., Kunst und Farbe, Otto Maier Verl. Ravensburg, 1970

[2] Panton V., "Choosing colours should not be a gamble. It should be a conscious decision. Colours have meaning and function" as a title of his booklet, Danish Design Centre 1997

[3] Hutchings J.B., Color in anthropology and folklore, in Color for science, art and technology, ed. by: K Nassau, Elsevier, Amsterdam, 1998

[4] Robertson D., Davies I., Davidoff J, Color categories are not universal: replications and new evidence from stone-age culture. $J$. of Exp. Psychology: 2000, General 129. 369-98

[5] Berlin B., Kay P., Basic Color Terms. Their Universality and Evolution, Berkeley: University of California Press, Reprinted 1991

[6] Heider E.R., Oliver D.C., The structure of the colour space in naming and memory for two languages, Cogn. Psychol., 1972; 3:337-354 
[7] Davidoff J., Davies I., Roberson D., Colour categories in a store-age tribe. Nature, 1999; 398:203-204

[8] Brown R.W., Lenneberg E.H., A study in language and congnition, $J$ Abnorm Psychol. 1954;49:454-462

[9] Thierry G., Athanasopoulos P., Wiggett A., Dering B., Kuipers J-R., Unconscious effects of language-specific terminology on preattentive color perception, Proc Natl Acad Sci USA, 2009;106(11): 4567-4570

[10] Winawer J. et al. Russian blues reveal effects of language on color discrimination. Proc Natl Acad Sci USA, 2007; 104:7780-7785

[11] Gilbert A.L., Regier T., Kay P., Ivry R.B., Whorf hypothesis is supported in the right visual field but not the left. Proc Natl Acad Sci USA. 2006; 103:489-494

[12] Drivonikou G.V., et al. Further evidence that Whorfian effects are stronger in the right visual field than the left. Proc Natl Acad Sci USA. 2007; 104:1097-1102

[13] Duncan, J.,Nobs, H.J., “Coloring our emotions: the measurement and application of our responses to color", Abstract. PICS 04 Conference Glasgow, 2004

[14] Szabó F., Bodrogi P., Schanda J. Experimental Modelling of Colour Harmony, Color Research and Application, 2010, 35(1): 34-49, 10.1002/col.20558, ISSN: 0361-2317, Online ISSN: 1520-6378

[15] Szabó F, Bodrogi P., Schanda J. A Colour Harmony Rendering Index based on new Colour Harmony Formulae, Lighting Research and Technology 2009 41: 165-182, Online ISSN: 1477-0938 Print ISSN: 1477-1535

[16] Brown, D.J., Neale H., Cobb S.V., Reynolds H, The development and evaluation of the virtual city. International Journal of Virtual Reality. (1999), 4(1):.28-41

[17] Standen P.J., BrownD.J. Virtual reality in the rehabilitation of people with intellectual disabilities: Review Cyberpsychology and Behaviour, (2005) 8, 3, pp. $272-282$

[18] Brown D.J., Shopland S., Battersby S., Tully A., Richardson S. (2009) Game On: Accessible serious games for offenders and those at risk of offending. Journal of Assistive Technologies, (2009) 3(2):15-30. (C) Pavilion Journals (Brighton) Ltd.

[19] Sik Lanyi C., Brown D., Standen P, Lewis J.,'Butkute V. (2012) Results of user interface evaluation of serious games for students with intellectual disability, Acta Polytechnica Hungarica, 2012, 9(1):225-245, ISSN: 17858860, http://www.uni-obuda.hu/journal/Issue33.htm 
[20] Komlodi, A., Hercegfi, K. Exploring Cultural Differences in Information Behavior Applying Psychophysiological Methods. CHI2010 (ACM Conference on Human Factors in Computing Systems), April 10-15, 2010, Atlanta, GA, USA, Proceedings pp. 4153-4158, ACM Press, ISBN:978-160558-930-5: http://portal.acm.org/citation.cfm?doid=1753846.1754118

[21] Clemmensen, T., Hertzum, M., Hornbaek, K., Qingxin, S., Yammiyavar, P. Cultural cognition in usability evaluation. Interacting with Computers (2009) 21: 212-220

[22] Hall, E.T.The Hidden Dimension. Doubleday, New York, NY, USA, 1990

[23] Gao X-P., Xin J.H., Sato T., Hansuebsai A., Scalzo M., Kaiwara K., Guan S-S., Valldeperas J., Lis M.J., Billger M., Analysis of CrossCultural Color Emotion, Color Research \& Application, 2007;32(3):223-229

[24] Sato T., Kajiwara K., Hoshino H., Nakamura T., Quantitive evaluation and categorization of human emotion induced by colour. Adv Colour Sci Technol. 2000;3:53-59

[25] Bowman D.A., Kruijff E., Laviola Jr. J.J., Poupyrev I., 3D User Interfaces. Addison-Wesley, 2004

[26] Komlódi A., Józsa E., Hercegfi K., Kucsora Sz., Borics, D. Empirical Usability Evaluation of the Wii Controller as an Input Device for the VirCA Immersive Virtual Space. CogInfoCom 2011, Budapest, Hungary, 2011 July 7-9., Proc. pp.1-6. ISBN 978-1-4577-1806-9

http://ieeexplore.ieee.org/xpls/abs_all.jsp?arnumber=5999481\&tag=1

[27] Komlódi A., Hercegfi K., Józsa E., Köles, M. Human-information interaction in $3 \mathrm{~d}$ immersive virtual environments. CogInfoCom $2012-3^{\text {rd }}$ IEEE International Conference on Cognitive Infocommunications, Kosice, Slovakia, 2012 Dec 2-5. Proc. pp.597-600. http://ieeexplore.ieee.org/xpl/articleDetails.jsp?arnumber=6422049

[28] Steinkuehler, C., Massively Multiplayer Online Games - Based Learning, M3 - Interdisciplinary Aspects on Digital Media \& Education, Workshop, Wien, Austria, Nov. 23, 2006, pp. 15-16

[29] Barfield W., Hendrix C., Bjorneseth O., Kaczmarek K.A., Lotens W., Comparison of human sensory capabilities with technical specifications of virtual environment equipments, Presense: Teleoperators and Virtual Environments, 4, 329-356

[30] Witmer B.G., Bailey J.H., Knerr B.W.. 1996, Virtual spaces and real world places: transfer of route knowledge, International Journal of HumanComputer Studies, 45, 413-428

[31] Wilson J.R., Virtual environments and ergonomics: needs and opportunities, Ergonomics, 1997, 40(10): 1057-1077 
[32] Sik Lányi C., Schanda J.: Analysing the Colours of the Virtual Reality Museum's Picture, Acta Polytechnica Hungarica, 2011, 8(5):137-150

[33] MacDonald L. (1998), Color in Computer Graphics, Lecture Notes, 2nd edition, MacColor Ltd.

[34] CIE Draft standard: Colorimetry - Part 4, (2006), CIE 1976 L*a*b* color space, CIE DS 014-4.1

[35] Sik Lányi C., Investigating of Memory - Colors of Intellectually Disabled Children and Virtual Game Addict Students, Lecture Notes in Computer Science, LNCS 5889, USAB 2009, Springer Verlag Berlin-Heidelberg, pp. 463-475

[36] Bartleson, C.J., Memory colors of familiar objects. J. OSA 50 73-77. (1960)

[37] Tarczali, T., Investigation of color memory, $\mathrm{PhD}$ thesis, University of Pannonia, 2007

[38] CIE TC 1-33 Color Rendering. Specifying Color Rendering Properties of Light Sources, 1996

[39] Sik Lányi C., Sik A., Sik G., What Kinds of Colors are Used in the Virtual Games, 12th International Conference, HCI International 2007, Beijing, China, July 22-27, 2007. Lecture Notes in Computer Science, LNCS 45504566, poster, pp. 1285-1288

[40] Sik Lányi C., Végh, V., Schanda, J., Cultural differences in cartoon colours, COST N529 Efficient Lighting for the 21st Century, Workshop WG4 Colour Aspects for Light Sources - Colorimetry and it's Applications in Industry ad Environment, Varna, Bulgaria, pp. 29-31 May 2006, 35-40 